\title{
ECONOMIA POLÍTICA DO TERRITÓRIO E AS FORÇAS DE DISPERSÃO E CONCENTRAÇÃO NO AGRONEGÓCIO BRASILEIRO
}

\author{
SAMUEL FREDERICO ${ }^{1}$
}

Universidade Estadual Paulista

Resumo: No início do século XXI a adoção pelo Estado brasileiro de uma política de estímulo às exportações, sobretudo de produtos primários, conjugada com a significativa elevação dos preços das principais commodities agrícolas no mercado internacional, tem provocado alterações na dinâmica territorial das áreas de agricultura moderna, constituindo-se uma economia política do território fundada no agronegócio. Dentre os diversos eventos vinculados a essa dinâmica territorial, enfatizamos neste artigo a relação entre as forças centrífugas decorrentes da dispersão das atividades modernas, em particular da aceleração no ritmo de expansão da fronteira agrícola; e as forças centrípetas, exemplificadas pelo reforço do papel de comando exercido pela metrópole de São Paulo. Palavras-chave: Fronteira Agrícola Moderna; Metrópole de São Paulo; Economia Política do Território; Forças Centrífugas e Centrípetas.

\section{TERRITORIAL POLITICAL ECONOMYAND FORCES OF DISPERSION AND CONCENTRATION IN BRAZILIAN AGRIBUSINESS}

Abstract: At the beginning of the 21stcentury, the Brazilian state adopted an export stimulus package focused primarily on the primary sector, following as harpincreasein prices of agricultural commodities in the international market. This process is leading to changes in the territorial dynamics

${ }^{1}$ Professor doutor do Departamento de Geografia da Universidade Estadual Paulista "Júlio de Mesquita Filho" (UNESP) - Rio Claro. Contato: sfrederico@ rc.unesp.br. 
of the areas of modern agriculture, giving rise to a territorial political economy based on agribusiness. Among the various examples which we could have taken to demonstrate this territorial political economy, we directed attention to the relationship between centrifugal forces, tied to the advance of the agricultural frontier, and centripetal forces, stemming from the strengthening of the decisionmaking power of some points in the territory, especially the commanding role of the metropolis of São Paulo.

Keywords: Modern Agricultural Frontier; Metropolis of São Paulo; Political Economy of the Territory; Centrifugal and Centripetal Forces.

\section{Introdução}

Durante a década de 2000 a adoção pelo Estado brasileiro de políticas de reforço à exportação de produtos primários, conjugada com a significativa elevação dos preços das principais commodities agrícolas no mercado internacional, levou à conformação de uma economia política do território fundada no agronegócio (SANTOS, 1994; DELGADO, 2012). Desde então o território brasileiro tem sido usado $^{2}$ (SANTOS; SILVEIA, 2001; SILVEIRA; 2010) em face das diferentes estratégias e do jogo político dos principais agentes envolvidos no agronegócio globalizado (ELIAS, 2011) - incluindo o Estado, grandes produtores, proprietários de terras, empresas agrícolas e investidores financeiros.

Desde o início da década de 1990 a subordinação do Estado brasileiro às indissociáveis lógicas financeira e liberal tem resultado na ampliação de políticas de reforço às exportações (SANTOS, 1999). Contudo, para Delgado (2012), com a crise cambial de 1999 a política de aumento das exportações tornou-se ainda mais agressiva, com o intuito de gerar saldos de comércio exterior para o pagamento dos serviços da dívida externa e para suprir o déficit de conta corrente e reverter a consequente redução das reservas internacionais. Para isso, houve uma reestruturação da economia do agronegócio com forte atuação do Estado: na reativação do crédito rural para a produção agroexportadora ${ }^{3}$; na regulação frouxa do mercado de terras, ao facilitar a apropriação de áreas devolutas ${ }^{4}$; na política cambial de desvalorização do Real (ao menos num primeiro momento), essencial para o aumento das exportações de produtos primários; no fornecimento de crédito

\footnotetext{
${ }^{2}$ A noção de território usado faz referência à implantação e ao uso diferenciado de infraestruturas ou sistemas de engenharia decorrentes do dinamismo da economia e da sociedade (SILVEIRA, 2010).

${ }^{3}$ Dentre os principais mecanismos de crédito rural, destacam-se: os planos de custeio, investimento e comercialização de safras; e o financiamento para aquisição de infraestruturas, como o Moderinfra.

${ }^{4}$ Segundo estimativas feitas por Sauer e Leite (2011), baseados em dados do Sistema Nacional de Cadastro Rural (INCRA), existem no Brasil cerca de 170 milhões de hectares de terras devolutas, o equivalente a $20 \%$ do território nacional.
} 
via Banco Nacional de Desenvolvimento Econômico e Social (BNDES) para aquisições e fusões entre empresas brasileiras e internacionais e para a remodelação de algumas plantas agroindustriais; e na articulação de pesquisas desenvolvidas pela Embrapa com empresas globais.

Acrescente-se também a construção e o financiamento de infraestruturas de transporte e armazenamento com o intuito principal de facilitar a logística de escoamento dos grãos, como a pavimentação da BR-163 (trecho paraense), a expansão das ferrovias Ferronorte e Norte-Sul e a modernização de portos como o de Itaqui, no Maranhão. Ainda segundo Delgado (2012), as ações anteriormente mencionadas configuram-se como um "novo projeto de acumulação de capital no setor agrícola", estimulado e organizado pela política macroeconômica e financeira do Estado brasileiro, com forte impacto na elevação da renda da terra beneficiando grandes produtores e proprietários de terras -, e também na centralização de capital no ramo agroindustrial, com o surgimento de megaempresas de inserção internacional, como a BRF (BrasilFoods) e a JBS ${ }^{5}$.

Em decorrência da celeuma em torno da noção de agronegócio, não nos restringimos à proposta de Davis e Goldberg (1957) de que o termo designaria um novo ramo de atividade econômica que inclui, além da produção agrícola propriamente dita, sua relação com a indústria de suprimentos a montante e com o processamento agroindustrial a jusante. Como afirma Delgado (2012), esta é uma noção meramente técnica e descritiva, isto é, que apresenta grande quantidade de dados e informações, mas sem poder teórico-explicativo das relações econômicas e sociais. Para isso seria necessário que a noção desvendasse também o sentido das relações, ou seja, as estratégias de acumulação dentro do setor. No caso brasileiro elas seriam indissociáveis de uma compreensão sobre a dinâmica do mercado de terras e do sistema de crédito subsidiado, ambos com forte atuação estatal. Daí a proposta de Delgado (2012) de não incluir apenas as cadeias agroindustriais na análise do agronegócio, mas também os proprietários de terras e o Estado.

Ao analisar as transformações no campo argentino a partir da década de 1990, Gras e Hernandez (2013) também propõem uma interpretação da ideia de agronegócio que, de certa forma, corrobora e complementa a proposta de Delgado (2012). Para as autoras a noção incluiria, além dos vínculos característicos dos complexos agroindustriais, uma série de novas articulações e relações

\footnotetext{
${ }^{5}$ Essas empresas se constituem como os maiores conglomerados alimentícios brasileiros produtores e exportadores de carnes. Ambas tiveram expressivo crescimento a partir da segunda metade da década de 2000, com forte suporte financeiro do Estado. Enquanto a BRF surgiu da fusão entre a Perdigão e a Sadia (duas das maiores empresas brasileiras de alimentos), a JBS se expandiu a partir da aquisição de grandes empresas de alimentos em outros países, como a Swift na Argentina e EUA.
} 
institucionais crescentemente controladas por empresas globais e instituições financeiras em substituição aos organismos públicos.

Trata-se de uma nova lógica de produção caracterizada por transformações de ordem técnica (inovação tecnológica constante dos insumos químicos, biológicos e maquinário), política (menor intervenção direta do Estado e maior poder de regulação das corporações mundiais), financeira (altos requerimentos de capital e participação crescente do capital financeiro) e produtiva (reorganização do trabalho, aumento da composição orgânica do capital, organização de redes de empresas com crescente concentração e centralização de capital) que ocorreram em parte significativa da agricultura mundial especialmente a partir do final da década de 1990.

Numa perspectiva geográfica, a ideia de agronegócio refere-se à emergência do que Santos (2000, p. 88) denominou de agricultura científica globalizada. Para o autor, trata-se de uma produção agrícola com "referência planetária" conduzida sob as mesmas leis das demais atividades econômicas - com crescente importância do papel da ciência, tecnologia, informação e do dinheiro. Dentre as expressões político-geográficas derivadas das novas relações estabelecidas pela agricultura científica globalizada no território brasileiro ressalta-se: a aceleração na constituição de novas regiões produtivas ${ }^{6}$ (ELIAS, 2011); a implantação de capitais fixos (rodovias, ferrovias, portos, cidades, sistemas de comunicação etc.); a crescente especialização territorial produtiva em commodities agrícolas destinadas, sobretudo, ao mercado externo; o alargamento da divisão territorial do trabalho das grandes empresas e atividades produtivas (SANTOS, 1994); a maior centralidade da logística (CASTILLO, 2011); assim como a crescente subordinação dos produtores locais a uma lógica global em que possuem cada vez menor poder de controle.

Dessa forma, acreditamos que a noção de economia política do território proposta por Santos (1994) pode ser um caminho para a interpretação da reestruturação produtiva e da dinâmica territorial brasileira vinculada ao agronegócio no início do século XXI. Para o autor (1994), dentre as diferentes acepções assumidas historicamente pelo termo economia política pode-se admitir, ainda que de forma simplificada, que a noção se refere principalmente ao estudo das relações de produção. Enfatiza-se, em particular, as condições de realização e de distribuição do excedente econômico como resultado, em última instância, das

\footnotetext{
${ }^{6}$ Para Elias (2011, p. 153), a região produtiva agrícola caracteriza-se como os "novos arranjos produtivos agrícolas", que concentram a maior parte dos investimentos produtivos com forte presença das redes agroindustriais crescentemente globalizadas.
} 
complexas relações entre capital e trabalho, proprietários e não-proprietários. Todavia, conforme relembra o próprio autor (1979; 1994), não há como pensar uma economia política sem levar em consideração o dado espacial. O intuito é compreender como a realização e as consequências de determinada produção organizam o território. E, de forma indissociável, como as condições naturais e socialmente construídas também condicionam a produção num movimento único e dialético.

As áreas de difusão do agronegócio no Brasil são um dos melhores exemplos da imbricada relação anteriormente mencionada. Nelas ocorre um verdadeiro rearranjo do território para atender às demandas do agronegócio globalizado (SANTOS, 2000; ELIAS, 2011). Por um lado, as relações de poder entre os principais agentes do agronegócio (agroindústrias, produtores, proprietários fundiários e Estado) possuem papel central na organização territorial ao induzir a instalação de infraestruturas, a criação de cidades, o movimento populacional, o mercado de trabalho, a estrutura fundiária e as características produtivas. Por outro lado, mas de forma indissociável, a dimensão continental do território brasileiro, a existência de áreas propícias à expansão da agricultura moderna, as condições fisiográficas favoráveis (solo, pluviosidade, reservas hídricas e relevo) e a presença seletiva de infraestruturas (rodovias, ferrovias, hidrovias, armazéns, energia) também condicionam a qualidade, os custos, a localização e a produtividade agrícola.

Dentre as diversas formas de se demonstrar como se estrutura esta nova economia política do território, este artigo analisa, ainda que de forma não acabada, o movimento de articulação entre as forças centrífugas e centrípetas (SANTOS; SILVEIRA, 2001). Para isso, analisaremos a relação entre a expansão da fronteira agrícola moderna (forças centrífugas) e a centralização do comando produtivo, em particular na metrópole de São Paulo (forças centrípetas).

Como metodologia de análise das referidas forças de dispersão e concentração, utilizamos para o primeiro caso dados da Produção Agrícola Municipal do Instituto Brasileiro de Geografia e Estatística (PAM/IBGE) para quantidade produzida e área plantada de lavouras temporárias - particularmente soja - nas Mesorregiões do IBGE que compõem o que estamos denominando por fronteira agrícola moderna, entre 2000 e 2013 (explicitado na segunda parte do artigo). Para as décadas anteriores (1970/80/90) utilizamos os dados do Censo Agropecuário do IBGE $(1970 ; 1980 ; 1985 ; 1990 ; 1996)$ por Unidade da Federação.

Para demonstrar o papel de comando da metrópole de São Paulo utilizamos dados sobre a localização das sedes corporativas das 50 maiores empresas do agronegócio brasileiro em 2011 (REVISTA EXAME, 2011), o número crescente 
de empresas com capital aberto na Bolsa de Valores de São Paulo (BMF\&Bovespa) e o importante papel da intermediação financeira, sobretudo na oferta de grandes montantes de crédito. Para isso, além do levantamento e análise de dados secundários disponíveis no Ranking das Maiores Empresas do Agronegócio (2011), da Revista Exame; nos websites das empresas; na Comissão de Valores Imobiliários (CVM) e no Banco Central do Brasil (Anuário Estatístico do Crédito Rural), realizamos uma série de trabalhos de campo com entrevistas semiestruturadas com diretores e gerentes de empresas do agronegócio entre 2013 e 2015, com obtenção de dados primários ${ }^{7}$.

Dessa forma, este artigo está divido em quatro partes, incluindo esta Introdução e as considerações finais. No segundo item, denominado Forças Centrífugas e Expansão da Fronteira Agrícola Moderna, analisa-se como as políticas de estímulo às exportações resultaram na reaceleração do ritmo de expansão da fronteira agrícola moderna a partir da primeira década do século XXI. Para tanto, fez-se uma retrospectiva do movimento centrífugo da produção agrícola moderna no território brasileiro desde a década de 1970. Na parte seguinte, denominada Forças Centrípetas e o Papel de Comando da Metrópole de São Paulo, demonstrase como o movimento de dispersão das atividades modernas está articulado com o crescente papel de controle exercido pela metrópole paulistana, particularmente pela presença das sedes corporativas das principais empresas do agronegócio e pelo papel exercido pela Bolsa de Valores de São Paulo e pelas instituições financeiras.

\section{Forças centrífugas e expansão da fronteira agrícola moderna}

Denominam-se aqui por fronteira agrícola moderna as áreas do território brasileiro ocupadas a partir da década de 1970 por monoculturas intensivas em capital e tecnologia em larga escala, destinadas, sobretudo, à exportação em substituição à vegetação original, às culturas tradicionais (praticadas por camponeses) e às áreas de pastagens extensivas. Grosso modo, essas áreas

\footnotetext{
${ }^{7}$ No período analisado (2013 a 2015), realizamos uma série de visitas técnicas às empresas do agronegócio na Metrópole de São Paulo e nas áreas de fronteira agrícola, principalmente, nos estados do Mato Grosso e Bahia. No total foram visitadas 17 empresas de diversos tipos (logística; tradings; alimentícias; agrícolas) e tamanhos (desde grupos familiares até empresas globais).
} 
coincidem com a abrangência do Domínio Morfoclimático do Cerrado $^{8}$ que, segundo Ab'Saber (2003, p.117), é um dos "grandes polígonos irregulares que formam o mosaico paisagísticos brasileiro". Com uma área de aproximadamente 2 milhões de $\mathrm{km}^{2}$, equivalente à $1 / 4$ da extensão territorial brasileira, o Cerrado possui condições topográficas (planalto com grandes áreas planas e solos profundos) e climáticas (pluviosidade regular e em volume adequado e intensa luminosidade) favoráveis à mecanização e à produção agrícola em larga escala.

Como proposto por Santos e Silveira (2001, p.119), a ideia de fronteira é utilizada em oposição à noção de belt, isto é, as áreas mais tradicionais de produção agrícola moderna do território brasileiro. Para os autores, enquanto os "belts são, por vezes, heranças e cristalizações de fronts próprios de uma divisão territorial do trabalho anterior", a fronteira (por eles denominada fronts) corresponde aos territórios incorporados pela agricultura moderna a partir do último quartel do século XX. De maneira geral e com o objetivo de facilitar o levantamento e a organização de dados estatísticos, consideramos que as áreas de produção agrícola moderna das regiões Sul e Sudeste (com exceção das Mesorregiões do IBGE do Triângulo Mineiro/Alto Parnaíba e Noroeste, no estado de Minas de Gerais) configuram-se como belts, enquanto as áreas modernas produtoras de grãos das regiões Centro-Oeste ${ }^{9}$, Norte ${ }^{10}$ e Nordeste ${ }^{11}$ conformariam o que aqui se denomina por fronteira agrícola moderna. O Mapa 1 mostra as mesorregiões que compõem as áreas de fronteira (verde) e os belts (violeta). A partir do mapa também é possível verificar a quase coincidência da extensão do Domínio de Cerrado (marrom claro) com a abrangência da fronteira agrícola moderna.

\footnotetext{
${ }^{8}$ Para Ab’Saber (2003), os domínios morfoclimáticos caracterizam-se por uma unidade paisagística passível de ser individualizada, resultado da combinação de um conjunto de elementos que se autocondicionam como: relevo, clima e vegetação, incluindo também a própria ação antrópica.

${ }^{9}$ Centro-Norte de Mato Grosso do Sul - MS; Leste de Mato Grosso do Sul - MS; Sudoeste de Mato Grosso do Sul - MS; Norte Mato-Grossense - MT; Nordeste Mato-Grossense - MT; Sudoeste MatoGrossense - MT; Centro-Sul Mato-Grossense - MT; Sudeste Mato-Grossense - MT; Noroeste Goiano - GO; Norte Goiano - GO; Leste Goiano - GO; Sul Goiano - GO; Distrito Federal - DF.

${ }^{10}$ Leste Rondoniense - RO; Sudeste Paraense - PA; Oriental do Tocantins - TO e Ocidental do Tocantins - TO.

${ }^{11}$ Leste Maranhense - MA; Sul Maranhense - MA; Sudoeste Piauiense - PI; Extremo Oeste Baiano BA.
} 


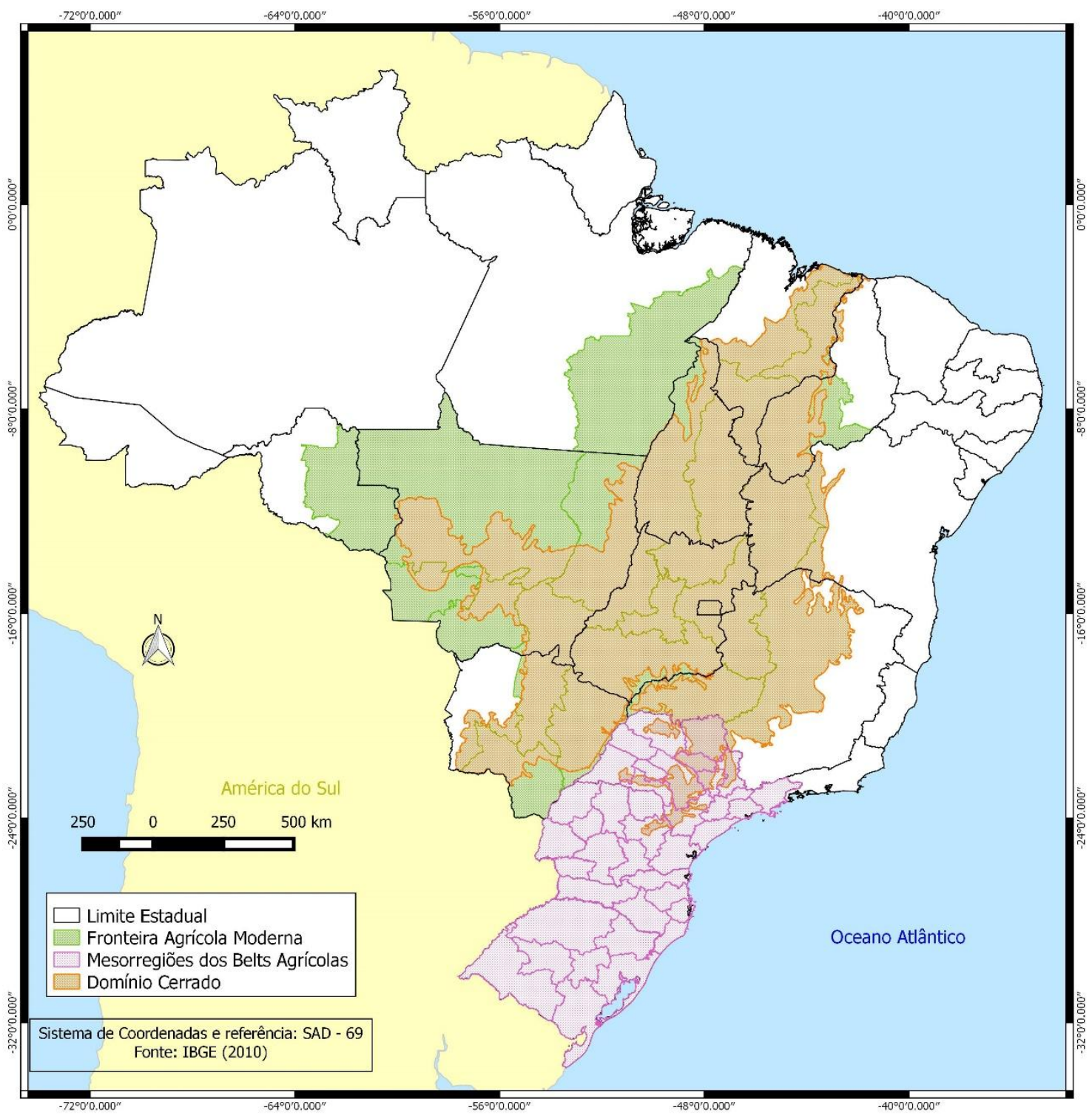

Mapa 1: Fronteira Agrícola Moderna, Belts, Domínio Cerrado e Mesorregiões IBGE. 
Importante ressaltar que a fronteira agrícola moderna não é uma região homogênea. Apesar de possuir alguns eventos comuns de grande envergadura que a caracteriza, como a presença de uma agricultura intensiva em capital e tecnologia em grandes propriedades e destinada especialmente à exportação, com forte presença de tradings internacionais (ADM, Bunge, Cargill e Louis Dreyfus), grandes produtores e intensos conflitos pela posse da terra, ela pode ser subdividida de diferentes maneiras. Para Frederico (2010), apoiado em Bernardes (2006), pode-se verificar a existência de uma fronteira consolidada e outra em expansão. Enquanto a primeira caracteriza-se pelas áreas pioneiras de ocupação das décadas de 1970/80 (faixa meridional), com a presença mais consolidada de sistemas técnicos (cultivares e técnicas de manejo adaptados) e infraestruturas (especialmente de transporte e armazenagem); as áreas de expansão (que corresponde à franja da fronteira) configuram-se pela presença de maiores estoques de terras passíveis de serem incorporados, com preços menores, por vezes carentes de infraestruturas e cultivares adaptados.

Apesar de contínuo, o ritmo de expansão da fronteira agrícola apresentou três momentos distintos entre 1970 e 2010. Duas fases de forte expansão, uma entre 1970-1985 e outra entre 2000-2010, estimuladas, sobretudo, pela política estatal de aumento das exportações de produtos primários, com grande oferta de crédito rural subsidiado (DELGADO, 1985; 2012); intercaladas por uma fase intermediária, entre 1985 e 2000 , momento em que a fronteira também se expande, porém num ritmo inferior $^{12}$. Nesta fase, marcada pela crise cambial e fiscal do Estado brasileiro (anos 1980) e pela adoção da ideologia e das políticas neoliberais (anos 1990) (PECK; TICKEL, 2002; HARVEY, 2004), houve uma significativa diminuição do crédito público para a atividade agrícola, com importante repercussão no ritmo de expansão da fronteira.

A primeira fase (1970-85) se caracterizou por uma política deliberada de ocupação do Cerrado por parte do Estado, dentro de um contexto econômico e geopolítico. Na perspectiva econômica pretendia-se integrar os denominados fundos territoriais (MORAES, 2000), isto é, as áreas de reserva passíveis de serem incorporadas ao modo de produção dominante. A intenção era aumentar a

\footnotetext{
${ }^{12}$ Importante ressaltar que os marcos anuais que delimitam os períodos são ilustrativos, criados para dar maior clareza à periodização proposta. Eles demarcam contextos semelhantes na dinâmica de expansão da fronteira. Contudo, não significa que determinado período começou exatamente no ano de 1970 e se encerrou pontualmente no ano de 1985. Pode-se afirmar que o primeiro período se estende do início da década de 1970 a meados da década de 1980, enquanto o segundo vai da segunda metade da década de 1980 até o início da década de 2000; e o último período inicia-se a partir de então.
} 
produção agrícola com vistas a ampliar as exportações e abastecer um país que se industrializava e se urbanizava. $\mathrm{O}$ aumento da produção de grãos permitia o fornecimento de matéria-prima para a crescente indústria nacional, ao mesmo tempo em que aumentava as exportações - gerando as divisas imprescindíveis para a execução da política de substituição de importações. Na perspectiva estratégica (geopolítica), especialmente por se tratar de um período sob controle de governos militares, a ideia era garantir a integridade do território nacional com a ocupação das áreas fronteiriças e a transferência da população das regiões mais densamente povoadas e de maiores conflitos fundiários, como o Nordeste (BECKER; EGLER, 1994; MACHADO, 1994).

Para alcançar tais objetivos, o Estado cumpriu um papel fundamental na capitalização de produtores e agroindústrias por meio da oferta de crédito subsidiado, com taxas abaixo da inflação via Sistema Nacional de Crédito Rural (1965-1980) (DELGADO, 1985). Os recursos financeiros permitiram expandir e modernizar as plantas agroindustriais e fomentaram a aquisição de máquinas e terras por parte dos produtores agrícolas. Conjuntamente com a política de oferta de crédito público, o Estado atuou também em outras importantes frentes de indução da expansão e modernização da agropecuária: a criação e difusão de novos cultivares pela Embrapa (com destaque para a soja), adaptados às menores latitudes do Cerrado em relação às tradicionais regiões produtoras do Sul e Sudeste; a assistência técnica aos produtores, introduzindo novas formas de uso e manejo do solo; a construção de sistemas de transporte e armazenagem com o intuito de viabilizar o escoamento das safras; e, por fim, a implantação de programas de colonização públicos e privados que estimularam a migração dos produtores, sobretudo da região Sul (FREDERICO, 2010).

De certa forma o Estado obteve êxito em seus objetivos, recuando os fundos territoriais e implantando uma agricultura monocultora em larga escala e intensiva em capital e tecnologia nas áreas de Cerrado do Brasil Central (DINIZ, 2006). Segundo dados dos Censos Agropecuários, entre 1970 e 1985 a área ocupada com lavouras na região Centro-Oeste (principal região de expansão da fronteira agrícola) aumentou em aproximadamente $200 \%$, de 2,4 para 7,1 milhões de hectares. Com relação à soja (principal cultura de exportação), em 1970 menos de $2 \%$ da produção nacional era colhida no Centro-Oeste. Com a expansão da fronteira este percentual aumentou para 20\%, em 1980; 40\%, em 1990; e alcançou 54\%, em 2012 (CENSO AGROPECUÁRIO, 1980; 1990; PAM/IBGE, 2014).

Contudo, a partir da década de 1980, uma nova fase de menor participação direta do Estado fez com que o ritmo de expansão da fronteira agrícola se arrefecesse. A área total ocupada com lavouras permanentes e temporárias na 
região Centro-Oeste recuou de 7 para 6,6 milhões de hectares entre 1985 e 1996 (CENSO AGROPECUÁRIO, 1985; 1996). Apenas a área plantada de soja teve um crescimento relativamente pequeno, de 3,9 para 5 milhões de hectares entre $1990 \mathrm{e}$ 1999 (PAM/IBGE, 2014).

Esse segundo momento (1985-2000) marcou o aumento da participação e do poder de regulação da produção pelas grandes empresas do comércio mundial de grãos, conhecidas como tradings (FREDERICO, 2010). Para a ampliação da produção do excedente elas passaram a atuar em antigas funções exercidas pelo Estado, especialmente nas atividades consideradas estratégicas, como o controle da circulação material (armazenamento, beneficiamento, transporte, venda de sementes e fertilizantes) e imaterial (financiamento, comercialização e exportação). No entanto, o Estado não se tornou ausente, continuou relevante em algumas áreas mais onerosas e menos interessantes para as tradings, como o financiamento de infraestruturas (ferrovias, hidrovias, portos), o fornecimento de parte do crédito de investimento e custeio e o desenvolvimento de novos cultivares agrícolas.

Porém, a partir dos anos 2000, o estabelecimento do mencionado pacto de economia política do agronegócio (DELGADO, 2012) resultou na reaceleração do ritmo de expansão da fronteira agrícola. Segundo dados da Produção Agrícola Municipal do IBGE, a área ocupada com lavouras temporárias na fronteira agrícola alcançou 24,2 milhões de hectares em 2012, ante 11,6 milhões em 2000. Dentre as principais culturas a área ocupada pela produção de soja mais que dobrou no mesmo período, de 6,4 para 13,8 milhões de hectares. Com isso, em 2012 a região de fronteira agrícola moderna havia se tornado a maior produtora brasileira de algodão $(96,5 \%)$, girassol $(90,5 \%)$, sorgo $(71,8 \%)$, soja $(64,1 \%)$, milho $(48 \%)$ e a segunda em cana-de-açúcar $(16,3 \%)$ e arroz $(10,7 \%)$. Com relação à área plantada de soja, enquanto na tradicional região produtora dos estados do Sul (RS, SC e PR) o crescimento foi de 50\% entre 2000 e 2012, nas regiões de expansão da fronteira agrícola moderna o crescimento foi muito mais acentuado: Centro-Oeste (108\%), Nordeste $(149 \%)$ e Norte $(840 \%)$. A Tabela 1 mostra o crescimento absoluto e percentual entre 2000 e 2012 da área plantada (ha) e da quantidade produzida (t) de soja nas Mesorregiões do IBGE, que no seu conjunto compõem o que estamos denominando por fronteira agrícola moderna. 


\begin{tabular}{|c|c|c|c|c|c|c|}
\hline Mesorregião & \multicolumn{2}{|c|}{ Área Plantada (ha) } & \multirow{2}{*}{$\begin{array}{l}\text { Cresc.\% } \\
\text { 2000/12 }\end{array}$} & \multicolumn{2}{|c|}{ Quantid. Prod. (t.) } & \multirow{2}{*}{$\begin{array}{l}\text { Cresc.\% } \\
\text { 2000/12 }\end{array}$} \\
\hline $\begin{array}{c}\text { Geográfica - } \\
\text { IBGE }\end{array}$ & 2000 & 2012 & & 2000 & 2012 & \\
\hline $\begin{array}{c}\text { Leste } \\
\text { Rondoniense/ } \\
\text { RO }\end{array}$ & 11.800 & 145.504 & $1133 \%$ & 36.222 & 468.809 & $1194 \%$ \\
\hline $\begin{array}{c}\text { Sudeste } \\
\text { Paraense/ PA }\end{array}$ & 2.020 & 87.204 & $4217 \%$ & 2.157 & 284.543 & $13092 \%$ \\
\hline $\begin{array}{l}\text { Ocidental do } \\
\text { Tocantins/ TO }\end{array}$ & 17.106 & 149.503 & $774 \%$ & 43.065 & 462.514 & $974 \%$ \\
\hline $\begin{array}{c}\text { Oriental do } \\
\text { Tocantins /TO }\end{array}$ & 40.813 & 265.960 & $552 \%$ & 101.297 & 814.414 & $704 \%$ \\
\hline $\begin{array}{c}\text { Leste } \\
\text { Maranhense/ } \\
\text { MA }\end{array}$ & 1.736 & 68.152 & $3826 \%$ & 4.958 & 135.808 & $2639 \%$ \\
\hline $\begin{array}{c}\text { Sul } \\
\text { Maranhense/ } \\
\text { MA }\end{array}$ & 176.370 & 480.872 & $173 \%$ & 448.359 & 1.485 .143 & $231 \%$ \\
\hline $\begin{array}{c}\text { Sudoeste } \\
\text { Piauiense/PI }\end{array}$ & 40.004 & 443.356 & $1008 \%$ & 100.963 & 1.238 .344 & $1127 \%$ \\
\hline $\begin{array}{c}\text { Extremo Oeste } \\
\text { Baiano/BA }\end{array}$ & 628.356 & 1.110 .157 & $77 \%$ & 1.508 .115 & 3.205 .298 & $113 \%$ \\
\hline $\begin{array}{l}\text { Noroeste de } \\
\text { Minas/MG }\end{array}$ & 136.395 & 389.350 & $185 \%$ & 316.331 & 1.147 .395 & $263 \%$ \\
\hline $\begin{array}{c}\text { Triângulo } \\
\text { Mineiro-Alto } \\
\text { Paranaíba/ MG }\end{array}$ & 445.651 & 565.070 & $27 \%$ & 1.092 .018 & 1.748 .213 & $60 \%$ \\
\hline $\begin{array}{c}\text { Centro Norte de } \\
\text { MS/MS }\end{array}$ & 274.910 & 390.178 & $42 \%$ & 709.570 & 1.146 .010 & $62 \%$ \\
\hline $\begin{array}{l}\text { Leste de Mato } \\
\text { Grosso do Sul/ } \\
\text { MS }\end{array}$ & 202.677 & 184.330 & $-9 \%$ & 508.664 & 562.044 & $10 \%$ \\
\hline $\begin{array}{l}\text { Sudoeste de } \\
\text { Mato Grosso do } \\
\text { Sul/MS }\end{array}$ & 628.514 & 1.230 .328 & $96 \%$ & 1.267 .466 & 2.866 .384 & $126 \%$ \\
\hline $\begin{array}{c}\text { Norte Mato- } \\
\text { Grossense /MT }\end{array}$ & 1.826 .504 & 4.607 .583 & $152 \%$ & 5.497 .870 & 14.427 .984 & $162 \%$ \\
\hline $\begin{array}{l}\text { Nordeste Mato- } \\
\text { Grossense/MT }\end{array}$ & 206.736 & 1.010 .280 & $389 \%$ & 630.140 & 3.135 .953 & $398 \%$ \\
\hline $\begin{array}{l}\text { Sudoeste Mato- } \\
\text { Grossense/MT }\end{array}$ & 28.463 & 82.495 & $190 \%$ & 81.896 & 264.059 & $222 \%$ \\
\hline Centro-Sul & 27.939 & 94.744 & $239 \%$ & 74.999 & 302.457 & $303 \%$ \\
\hline
\end{tabular}


Mato-

Grossense/MT

Sudeste Mato-

817.006

1.185 .588

$45 \%$

.489 .565

3.710 .839

$49 \%$

Grossense/MT

Noroeste

956

60.501

$6229 \%$

2.305

192.386

$8246 \%$

Goiano/ GO

Norte

19.530

98.490

$404 \%$

47.484

299.756

$531 \%$

Goiano/GO

Leste

111.530

432.060

$287 \%$

315.374

1.263 .843

$301 \%$

Goiano/GO

\begin{tabular}{ccccccc} 
Sul Goiano/ GO & 1.341 .432 & 2.019 .257 & $51 \%$ & 3.683 .035 & 6.466 .273 & $76 \%$ \\
$\begin{array}{c}\text { Distrito Federal/ } \\
\text { DF }\end{array}$ & 33.582 & 55.050 & $64 \%$ & 92.921 & 176.160 & $90 \%$ \\
Brasil & 13.693 .677 & 25.090 .559 & $64 \%$ & 32.820 .826 & 65.848 .857 & $90 \%$ \\
\hline
\end{tabular}

Tabela 1: Área plantada, quantidade produzida e crescimento percentual entre 2000 e 2012 de soja, fronteira agrícola moderna (Mesorregiões IBGE).

Fonte: PAM/IBGE, 2014.

Com poucas exceções, em todas as Mesorregiões que compõem a fronteira agrícola moderna a área plantada de soja teve um crescimento muito acima da média brasileira - de $64 \%$ entre 2000 e 2012. As exceções ficam por conta das Mesorregiões que se encontram na área de fronteira agrícola consolidada, onde o estoque de terras para a expansão da agricultura moderna encontra-se praticamente esgotado, como no caso do Extremo Oeste Baiano (BA), do Sudeste MatoGrossense (MT) e Distrito Federal (DF) e aquelas que combinam o esgotamento das terras com a concorrência de outras culturas, particularmente a cana-de-açúcar, como as do Centro-Norte e Leste do Mato Grosso do Sul, Sul Goiano (GO) e Triângulo Mineiro/Alto Parnaíba (MG). As regiões de maior destaque de crescimento da área plantada de soja são justamente aquelas localizadas na franja da fronteira, de incorporação mais recente, como as do Noroeste Goiano (6229\%), do Sudeste Paraense (4217\%), do Leste Maranhense (3826\%), do Leste Rondoniense (1133\%), do Sudoeste Piauiense (1008\%), do Ocidental (774\%) e Oriental do Tocantins (552\%). O Mapa 2 mostra a área plantada de soja em 2013 e o seu percentual de crescimento entre 2000 e 2013 por Mesorregião do IBGE na fronteira agrícola moderna. 


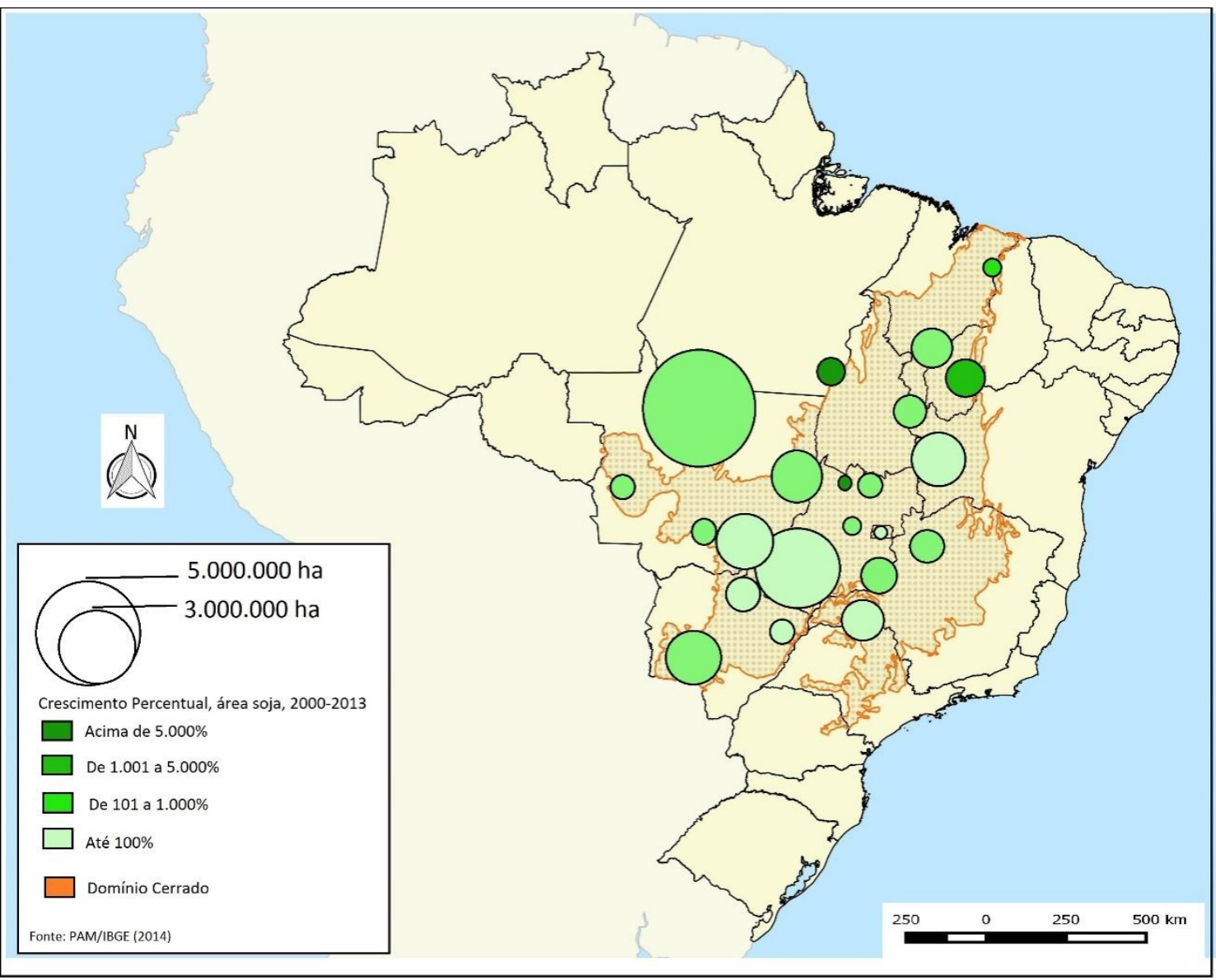

Mapa 2: Área Plantada (2013), Crescimento Percentual (2000-2013), Soja, Mesorregiões IBGE, Fronteira Agrícola Moderna.

Ao analisar mais detidamente as Mesorregiões observa-se que no Maranhão as plantações de soja se expandiram na região de Chapadinha, no Leste do estado, e na região Sul (a partir do município de Balsas); no Piauí a área cultivada da oleaginosa se expandiu na região Sudoeste a partir da divisa com o estado da Bahia; neste último o crescimento da área ocorreu no Extremo Oeste, partindo dos municípios de Barreiras e Luís Eduardo Magalhães em direção aos municípios de Formosa do Rio Preto (sentido norte) e Cocos (sentido sul); em Rondônia a soja entrou pela porção Leste a partir da divisa com o estado do Mato Grosso; no qual a 
expansão ocorreu de forma significativa em todas as Mesorregiões, com crescimento percentual pouco menor na região Sudeste, onde as terras propícias já se encontram praticamente ocupadas; em Goiás a área plantada se expandiu no entorno do Distrito Federal, seguindo em direção nordeste (Chapada dos Veadeiros e município de Flores de Goiás); no Pará a soja tem uma tendência de se expandir ao longo das rodovias BR 163 e BR 158, proveniente do estado do Mato Grosso; em Minas Gerais a área plantada de soja cresceu principalmente no Noroeste do estado, próximo à divisa com Goiás; no Mato Grosso do Sul as áreas de maior destaque de crescimento são o Sudoeste e o Centro-Norte do estado; por fim, a área plantada de soja também teve um aumento significativo em diferentes pontos do estado de Tocantins, particularmente próximos às divisas dos estados da Bahia e Maranhão, na sua parte Ocidental.

Junto com a expansão anteriormente descrita, há também uma crescente especialização territorial produtiva, isto é, o "aumento numa mesma região da diversificação de tarefas vinculadas a um mesmo processo, enquanto diminuem as demais técnicas e formas de trabalho" (SILVEIRA, 2010, p.79). Em 1990, dos 50 maiores municípios brasileiros produtores de soja 25 não se localizavam na fronteira agrícola. Em 2012, esse número havia se reduzido para apenas três (dois no estado do Paraná e um em Minas Gerais (PAM/IBGE, 2014). Neste último ano, dentre os quase 1.800 municípios brasileiros produtores de soja apenas 76 foram responsáveis por $50 \%$ do volume total, enquanto os 10 primeiros produziram $16 \%$ (PAM/IBGE, 2014). Somente o município de Sorriso (MT), maior produtor nacional, foi responsável por 3\% do total com uma produção de quase dois milhões de toneladas (PAM/IBGE, 2014). A especialização produtiva fica ainda mais evidente quando tomamos como exemplo o crescimento das culturas temporárias nos dez maiores municípios produtores de soja da fronteira agrícola ${ }^{13}$. Em todos eles a soma da área plantada de soja, milho e algodão alcançou mais de $90 \%$ da área total cultivada em 2012 (PAM/IBGE, 2014).

Como observado, os dados permitem verificar a reaceleração na expansão da fronteira agrícola a partir da década de 2000, com consequente aprofundamento da especialização territorial produtiva. Desde então houve um aumento da força centrífuga de dispersão da agricultura moderna, particularmente em áreas de Cerrado das regiões Centro-Oeste, Nordeste e Norte. Esse fenômeno foi estimulado especialmente pela elevação dos preços das principais commodities agrícolas nos

\footnotetext{
${ }^{13}$ Em ordem decrescente: Sorriso (MT), Sapezal (MT), Nova Mutum (MT), Campo Novo dos Parecis (MT), Formosa do Rio Preto (BA), Rio Verde (GO), Nova Ubiratã (MT), Querência (MT), Diamantino (MT) e Jataí (GO).
} 
mercados internacionais (especialmente a soja) e pelo aumento da disponibilidade de crédito estatal, como enfatizado na primeira parte do artigo. A seguir demonstra-se, baseado na proposta teórica de Santos (1996), como este movimento de diástole das atividades modernas se combina a uma força centrípeta de concentração do comando nas metrópoles, principalmente em São Paulo.

\section{Forças centrípetas e o papel de comando da metrópole de São Paulo}

Dialeticamente, o reverso da dilatação territorial da produção agrícola moderna é a centralização de seu comando, que também se intensificou a partir da década de 2000. Enquanto o controle técnico das operações produtivas é relativamente disperso - com a presença marcante de engenheiros, consultores e agrônomos nas regiões produtivas agrícolas (ELIAS, 2011) -, a regulação normativa, financeira e informacional tende a se concentrar num número seleto de lugares, como o caso da metrópole de São Paulo (SANTOS, 1994). Pode-se afirmar, mesmo que de forma ainda exploratória, que a metrópole paulistana é onipresente não apenas na fronteira agrícola, mas também na maioria das regiões brasileiras dedicadas à produção agrícola moderna.

A partir do início do século XXI a crescente centralização do capital no agronegócio verificada no território brasileiro (OLIVEIRA, 2010) também contribuiu para a redução do número de polos decisórios. Quando nacionais muitas empresas ao crescerem preferem transferir sua sede para as principais metrópoles, particularmente São Paulo. No caso de empresas estrangeiras ou nacionais incorporadas pelo capital internacional, a capital paulista acaba por exercer apenas um controle delegado, como um degrau intermediário entre a sede corporativa da empresa em outros países e as regiões produtivas brasileiras.

Das 50 maiores empresas do agronegócio brasileiro em 2011 (REVISTA EXAME, 2011) 25 possuíam sua sede na cidade de São Paulo: três das maiores tradings agrícolas internacionais (Cargill, ADM e Louis Dreyfus); a Unilever e a Granol, que atuam no ramo de óleos, farinhas e conservas; a empresa Noble, especializada em grãos e algodão; as principais empresas do setor sucroenergético (Raízen e Copersucar e LDC Bioenergia); as empresas Suzano, Klabin, Fibria e Duratex do ramo de madeira e celulose; os dois maiores frigoríficos nacionais (JBS e Marfrig); as duas mais importantes empresas do ramo de leite e derivados (Nestlé e Parmalat); além de grandes empresas de adubos e agrotóxicos (Basf, Bunge Fertilizantes, Bayer, Syngenta, Monsanto, Mosaic e DuPont). O Mapa 3 apresenta 
a localização da sede das 50 maiores empresas do agronegócio no território brasileiro em 2011.

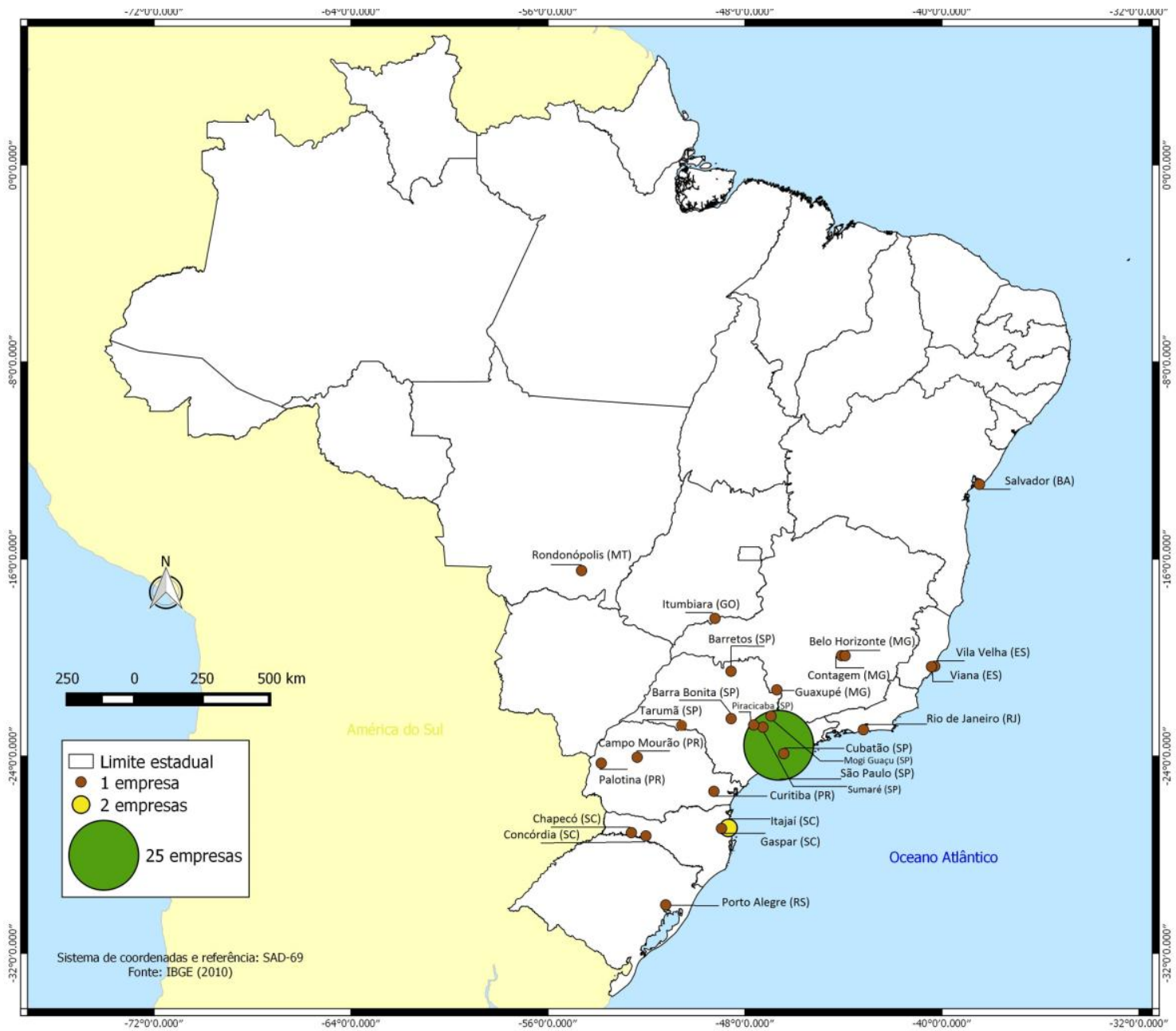

Mapa 3: Sede das 50 maiores empresas do agronegócio, Brasil, 2011

Depois da metrópole de São Paulo destaca-se o grande número de empresas do agronegócio com sede na região dos belts agrícolas, especialmente nos demais estados da região $\mathrm{Sul}$ - onde tem nove empresas - e no interior e litoral do estado de São Paulo, com sete empresas. Apenas duas empresas, dedicadas especialmente 
à comercialização e esmagamento de grãos, possuem sede na fronteira agrícola moderna, a Amaggi - originária do estado do Mato Grosso -, que possuía sua sede em Rondonópolis (MT) e a goiana Caramuru Alimentos - com sede em Itumbiara (GO). No primeiro caso ressalta-se a transferência da sede corporativa da empresa para a capital do estado do Mato Grosso (Cuiabá) e no segundo, a localização da sede num importante ponto logístico para a empresa, que se utiliza do porto fluvial de Itumbiara para o escoamento dos grãos ${ }^{14}$.

Ressaltam-se também as empresas com sedes em outras metrópoles, como a Souza Cruz, do ramo fumageiro, que tem sede na cidade do Rio de Janeiro; a estadunidense Kraft, do ramo alimentício, com sede em Curitiba (PR); a norueguesa Yara, fabricante de fertilizantes, com sede em Porto Alegre (RS); a brasileira Suzano, do ramo de madeira, papel e celulose - com sede em Salvador (BA); as empresas Heringer - especializada em adubos - e a Garoto, maior produtora de chocolate da América Latina, com sedes na Região Metropolitana de Vitória; assim como a holandesa Case New Holland, do ramo de maquinário agrícola, e a Itambé, do ramo de leite e derivadas, ambas com sede na Região Metropolitana de Belo Horizonte - a primeira na própria capital e a segunda na cidade vizinha de Contagem (MG).

Depois das regiões metropolitanas, o interior e o litoral do estado de São Paulo são os locais onde estão o maior número de sedes de empresas dentre as 50 maiores em 2011. Destacam-se as sedes corporativas das indústrias de maquinário agrícola Caterpillar - em Piracicaba (SP) - e Sotreq (Sociedade de Tratores e Equipamentos LTDA), em Sumaré (SP); da produtora de insumos nitrogenados e fosfatados, utilizados como adubos e defensivos agrícolas, Ultrafértil, em Cubatão (SP); do grupo Minerva, uma das principais produtoras e exportadoras mundiais de carne bovina, na cidade de Barretos (SP) ${ }^{15}$; da companhia estadunidense do ramo de papel e celulose, International Paper, com sede na cidade de Mogi Guaçu (SP), próxima à sua principal planta industrial.

Em 2011 as empresas do Grupo Cosan - a Cosan Alimentos e a Cosan Açúcar e Álcool - tinham suas sedes nas cidades de Tarumã (SP) e Barra Bonita (SP), respectivamente. Todavia, ambas as empresas tiveram seus escritórios corporativos transferidos para a cidade de São Paulo. A Cosan Alimentos, após ser comprada

14 O Porto de Itumbiara localiza-se no rio Paranaíba, integrante do sistema hidroviário dos rios Paraná-Tietê.

${ }^{15}$ Atualmente, a Minerva Foods é o segundo maior grupo brasileiro exportador de carne bovina, atrás somente da também brasileira JBS. Mesmo após uma série de fusões na década de 2000, a empresa manteve a matriz na sua cidade originária de Barretos (SP). Porém, assim como a maioria das grandes empresas do agronegócio, também possui um escritório corporativo na cidade de São Paulo. 
pela empresa brasileira Camil Alimentos, em 2012; e a Cosan Açúcar e Álcool, devido à criação da joint-venture Raízen com a petroleira Shell.

No interior dos demais estados das regiões Sul e Sudeste encontravam-se a sede de mais oito empresas em 2011. Dentre estas, três cooperativas, isto é, possuem forte ancoragem territorial quando comparadas com as empresas privadas, ao não conseguir se transferir facilmente para outras regiões. Em Minas Gerais está a Cooxupé (Cooperativa Regional de Cafeicultores em Guaxupé Ltda.), na cidade de Guaxupé (MG) - principal região cafeicultora do estado. No interior do Paraná encontram-se a Coamo Agroindustrial Cooperativa - com sede na cidade de Campo Mourão - e a cooperativa agroindustrial do segmento de aves e suínos C.Vale, com sede em Palotina.

Além das cooperativas, outras cinco empresas possuíam sua sede na região Sul, todas no litoral e interior do estado de Santa Catarina. A cidade de Itajaí se destacava por sediar duas das maiores empresas do ramo de suínos e aves, a BRF (Brasil Foods) e a Seara, assim como pela presença da empresa Bunge na cidade vizinha de Gaspar (SC). A presença na cidade e no entorno se devia à proximidade com o Porto de Itajaí, principal do estado e maior exportador de frango congelado do Brasil, com importante posição também nas exportações de carne suína. No oeste catarinense, importante região produtora de aves e suínos, a cidade de Concórdia mantinha a sede da empresa Sadia desde a sua fundação, em meados dos anos de 1940. Por fim, em Chapecó (SC) se localizava a sede de outra grande empresa do segmento, a Aurora.

Entretanto, a Bunge transferiu sua sede para São Paulo, a Seara também teve sua sede principal transferida para a capital paulista após ser adquirida pela JBS, em 2013, e com a finalização da fusão entre a Perdigão e Sadia, em 2012, o escritório de Concórdia passou a ter papel secundário nas grandes decisões da empresa.

Dessa forma, se em 2011 São Paulo já reunia a metade das sedes das 50 maiores empresas do agronegócio, desde então as fusões e aquisições envolvendo essas empresas fizeram com que a importância da metrópole paulistana aumentasse ainda mais. A criação da joint-venture Raízen, o término da fusão entre a Sadia e a Perdigão com a criação da BRF, a aquisição da Seara pela JBS e da Cosan Alimentos pela Camil Alimentos e a transferência da sede pela Bunge fizeram com que o número de escritórios aumentasse para 29 dentre as empresas pesquisadas. Além de concentrar o maior número de sedes corporativas, quase todas as demais empresas mencionadas possuem importantes escritórios corporativos ou comerciais na metrópole paulistana, apesar de algumas delas ainda manterem suas sedes nas suas cidades e estados de origem. 
A partir de seus escritórios corporativos e, sobretudo, do uso privilegiado dos sistemas técnicos de comunicação, as grandes empresas do agronegócio comandam a produção territorialmente dispersa. Nos escritórios localizados na metrópole de São Paulo são realizadas as grandes negociações (exportação, importação e empréstimos) e tomadas de decisões estratégicas (aquisições, articulações com empresas e logística). Segundo Castells (2003), as razões fundamentais para que as áreas metropolitanas continuem a crescer em tamanho e complexidade estão associadas à disponibilidade de infraestrutura, serviços e à qualificação da mão de obra. Acrescentamos ainda, baseado em Santos (1994), que as decisões políticas reforçam a capacidade dessas cidades de manipular a informação e comandar a vida em outros lugares.

Assim, as grandes empresas do agronegócio localizadas na metrópole de São Paulo utilizam-se da sinergia organizacional propiciada pela proximidade com os clientes para o sucesso de seus negócios. Os centros difusores de inovação, as instituições financeiras e as empresas de consultoria jurídica e de recursos humanos também constituem importantes fatores de aglomeração para a localização dos escritórios corporativos das empresas do agronegócio.

Como consequência da presença dos escritórios corporativos dessas empresas, o município de São Paulo se destaca como o maior exportador brasileiro de soja, açúcar, milho, etanol e carnes. Isso ocorre porque a maior parte das operações é realizada a partir dos escritórios localizados na cidade, independente da procedência dos produtos. Como afirma Silva (2001), a capacidade de produção e transmissão da informação garante à metrópole de São Paulo a regulação de um crescente número de tarefas territorialmente dispersas.

Por exemplo, no caso das tradings (ADM, Bunge, Cargill, Louis Dreyfus), a maioria das transações comerciais e decisões estratégicas são realizadas pelos escritórios corporativos localizados na capital paulista. Os escritórios dispersos pelas principais regiões produtivas realizam a negociação local de compra de grãos e venda de insumos diretamente com os produtores, contudo são os escritórios de São Paulo que realizam a maior parte das exportações e importações e decidem os prazos para entrega dos grãos, o volume a ser adquirido, os preços a serem pagos ao produtor e a logística de escoamento e embarque portuário dos grãos.

Dessa forma, as exportações são registradas na Secretaria de Comércio Exterior do Ministério do Desenvolvimento, Indústria e Comércio (Secex/MDIC) como tendo sido realizadas pelo município de São Paulo, mesmo que ele não seja efetivamente o produtor dos grãos e demais mercadorias exportadas. Por isso que, em 2013, o complexo soja (grãos e derivados) juntamente com o sucroenergético (açúcar e etanol) totalizaram 50\% do valor das exportações do município. 
Não obstante, enquanto o município de Sorriso (MT), maior produtor brasileiro de soja, com cerca de dois milhões de toneladas produzidas em 2012, exportou 1,47 milhão de tonelada (soja e derivados), totalizando US\$ 814 milhões, São Paulo, mesmo sem produzir um grão de soja, exportou 2,97 milhões de toneladas com valor aproximado de US\$ 1,6 bilhão, pouco mais de 5\% da quantidade e do valor das exportações brasileiras do complexo em 2013 (SECEX/MDIC, 2014).

Situação semelhante ocorre com as demais commodities agropecuárias, como é o caso dos produtos derivados da cana-de-açúcar, que representaram quase $30 \%$ das exportações paulistanas, com 5,23 milhões de toneladas e valor de US\$ 2,44 bilhões no mesmo ano (SECEX/MDIC, 2014). No caso do açúcar e do etanol, o grande volume de exportações realizado pelo município de São Paulo se deve à presença de importantes escritórios corporativos de empresas do setor, como a Raízen, a Copersucar e a LDC Bioenergia.

Além da onipresença na maioria das regiões brasileiras dedicadas à produção agrícola moderna, seu poder de comando transcende os limites nacionais e sua influência alcança as dinâmicas territoriais de outros países sul-americanos. A cidade de São Paulo começa a atrair também as sedes de empresas de outros países sul-americanos, como é o caso das argentinas Adecoagro e El Tejar. Após se tornarem duas das maiores empresas agrícolas na Argentina, se transferiram para o Brasil e outros países do Cone-Sul no início da década de 2000. Com o crescimento das operações em território brasileiro, ambas as empresas transferiram sua sede corporativa principal para a metrópole paulistana, de onde passaram a controlar as demais operações na Argentina, Uruguai, Paraguai e Bolívia, reforçando a hipótese do papel de comando exercido por São Paulo.

O primeiro caso é um dos melhores para ilustrar a divisão territorial do trabalho $^{16}$ entre as regiões produtoras e a metrópole paulistana. Enquanto nas cidades próximas às fazendas, como na região de fronteira agrícola do Oeste da Bahia, ficam os funcionários especializados na operação agrícola - gerente agrícola, administrativo e financeiro da fazenda; coordenador agronômico, de máquinas e operações (plantio/colheita); agrônomos e técnicos agrícolas. No escritório em São Paulo - localizado no Bairro de Moema, uma das regiões mais nobres da cidade - ficam os diretores geral e agrícola, a controladoria da empresa, o jurídico, a área de planejamento estratégico e a equipe comercial e financeira.

\footnotetext{
${ }^{16}$ Para Santos (1996), a divisão territorial do trabalho refere-se à repartição espacial do trabalho vivo e do trabalho morto, isto é, inclui tanto a distribuição e articulação das formas materiais (infraestruturas, fábricas, plantações, objetos técnicos em geral), quanto o trabalho sendo realizado.
} 
A manutenção do escritório em São Paulo é estratégica para a empresa, pois além da maior facilidade em encontrar trabalhadores qualificados, a sua localização possibilita também a realização de negócios face to face entre os diretores da empresa, consultores, gerentes de bancos e diretores de empresas de consultoria. É recorrente durante os trabalhos de campo nas empresas a menção à necessidade de contato pessoal entre os diretores executivos para a aquisição de grandes volumes de crédito e o estabelecimento de parcerias entre empresas.

A centralidade conferida à produção de commodities e as intrincadas relações entre a agricultura e o capital financeiro também têm reforçado o papel de comando da cidade de São Paulo. Desde o final do século XIX as principais bolsas mundiais (como Nova York, Chicago e Londres) atuam na regulação dos preços internacionais das commodities agrícolas, inclusive no Brasil, como a Bolsa de Santos para o café. Porém, com a adoção das políticas neoliberais e a denominada "desregulamentação" da economia mundial, especialmente a partir da década de 1980, o volume de negócios com commodities nas bolsas de mercadorias e futuros aumentou significativamente, assim como se concentrou em algumas delas.

No Brasil não tem sido diferente. A criação da BM\&FBovespa em 2008, pela fusão entre a Bolsa de Valores de São Paulo (Bovespa) e a Bolsa de Mercadorias e Futuros (BM\&F), reuniu as transações das demais bolsas brasileiras, tornando-a a principal reguladora do mercado futuro dos principais produtos agropecuários brasileiros: soja, café, milho, etanol e boi gordo. Na BM\&FBovespa também estão as ações da maioria dos monopólios empresariais criados na década de 2000, a partir da articulação entre grandes empresas nacionais entre si e com o capital estrangeiro: Brasil Foods, JBS, Marfrig e Minerva, do ramo alimentício; SLC Agrícola, Brasil Agro e Vanguarda, dedicadas à produção agrícola e ao mercado de terras; São Martinho, Açúcar Guarani, Cosan, Ecodiesel e Tereos, do ramo sucroenergético; Suzano, Fibria, Klabin, Duratex e Eucatex, do setor de madeira, papel e celulose; entre outras.

Nas finanças a metrópole paulistana também se destaca. São Paulo foi o município brasileiro que mais realizou empréstimos do crédito rural em 2012. Entre 2000 e 2012 o volume de crédito rural disponibilizado pelo município aumentou de cerca de $\mathrm{R} \$ 150$ milhões para quase $\mathrm{R}$ \$ 1,4 bilhão, alcançando aproximadamente $10 \%$ do total de crédito rural disponibilizado em todo o Estado de São Paulo (BCB, 2014). Apesar de o município possuir uma produção agropecuária praticamente insignificante, o volume expressivo de empréstimos se explica pela presença das maiores agências dos principais bancos nacionais e internacionais fornecedores de crédito agrícola: Banco do Brasil, Bradesco, Itaú, Rabobank, HSBC, Votorantim, ABC Brasil, Citybank, Santander etc. 
Muitas vezes os maiores empréstimos firmados entre bancos e empresas agrícolas exigem a participação pessoal dos respectivos CEO's ${ }^{17}$. Nas reuniões e almoços de negócios entre os diretores de ambas as instituições são decididas as principais cláusulas dos contratos com a participação da equipe jurídica, assim como são definidas as contrapartidas exigidas por alguns bancos para a realização dos empréstimos - como o fornecimento de informações estratégicas e a participação nos negócios futuros da empresa. Durante trabalhos de campo nas áreas de fronteira agrícola alguns grandes produtores também relatam a necessidade de se deslocarem para São Paulo para realizarem empréstimos pessoalmente com os gerentes das maiores agências bancárias. Muitos afirmam que os gerentes das agências locais muitas vezes não possuem autonomia de negociação, dependendo do volume de crédito requerido.

Portanto, se por um lado a busca por maior produtividade e rentabilidade sob as exigências do mercado globalizado leva à especialização produtiva, tornando-se recorrente no território brasileiro a constituição de subespaços em que predominam monoculturas agroexportadoras em grandes propriedades em detrimento de outras culturas e formas de produzir. Por outro, a crescente dependência do agronegócio com relação às finanças e às informações de cunho estratégico, jurídico, mercadológico, contábil e logístico torna ainda mais significativo o papel desempenhado pela metrópole de São Paulo na regulação da produção. Dessa forma, o território acaba por se conformar como um rendilhado de divisões territoriais do trabalho de determinadas atividades e empresas, isto é, pela distribuição e articulação dos lugares e regiões de interesse para a ação corporativa.

\section{Considerações Finais}

Dentre as acepções da etimologia do termo região está a ideia de reger. Todavia, hoje é cada vez menor o número de regiões com capacidade de dirigir a si mesmas (SANTOS, 1996). Para o autor (1997, p. 114) os "centros de poder" restringem-se àquelas regiões onde os sistemas de objetos e ações são mais densos, especialmente às grandes metrópoles nacionais e mundiais. Como consequência pode-se falar, grosso modo, de uma divisão territorial do trabalho entre "áreas do mandar" e "áreas do fazer" (SANTOS; 1997; SANTOS; SILVEIRA, 2001). As

${ }^{17}$ CEO é a sigla inglesa de Chief Executive Officer, que significa Diretor Executivo em português. O CEO é a pessoa com maior autoridade na hierarquia operacional de uma organização, é o responsável pelas estratégias e pela visão da empresa. 
primeiras são representadas pelos centros decisórios, onde se localizam as sedes das grandes empresas e instituições financeiras. Os agentes reunidos nestas áreas teriam a capacidade de pensar o território como um todo, enquanto um recurso passível de ser apropriado e usado dentro de sua lógica de acumulação. Já as áreas do fazer caracterizam-se por sua especialização e pelo controle meramente técnico da produção. Em geral, são áreas do fazer eficiente, porém obedientes aos ditames dos centros regulatórios.

Nos parece que as relações estabelecidas entre a metrópole de São Paulo e as regiões produtivas agrícolas (ELIAS, 2011) são um dos melhores exemplos da relação proposta pelos autores. Enquanto São Paulo reúne a maioria das sedes das principais empresas do agronegócio e as principais instituições financeiras e bancárias, as regiões produtivas caracterizam-se como compartimentos territoriais especializados e funcionais ao agronegócio. Essa relação se reforça com a globalização (SANTOS, 2000), isto é, com a maior ingerência externa das finanças e da informação sobre o campo moderno. Quanto mais se intensifica e se expande o agronegócio globalizado no território brasileiro, maior também é o poder de controle exercido pelas grandes corporações e instituições financeiras concentradas principalmente nas metrópoles. Daí a proposta deste texto de se pensar a crescente articulação entre as forças centrífugas, de difusão da produção agrícola moderna, e as forças centrípetas, de concentração dos polos de comando.

Como propõe Santos (1994), com a gradual difusão das redes de comunicação e transporte, sobretudo a partir da década de 1970, criou-se uma lógica unitária de funcionamento do território brasileiro com reforço do movimento combinado de dispersão territorial das atividades modernas (agricultura, indústria e serviços) e concentração do comando político, especialmente na metrópole de São Paulo.

No início do século XXI, as facilidades oferecidas pelo uso das novas tecnologias da informação associadas às políticas estatais de estímulo à expansão das atividades modernas vinculadas principalmente aos produtos primários reforçaram ainda mais a lógica supramencionada de sístole e diástole. Ainda que o controle técnico das operações produtivas seja relativamente disperso, sua regulação normativa, financeira e informacional é cada vez mais centralizada, mesmo que muitas vezes de forma delegada pelo exterior.

Evidencia-se, assim, uma crescente subordinação da ordem local aos interesses e ditames corporativos globais. Como consequência, se na lógica do Estado e das grandes empresas a nova economia política do território representa respectivamente soluções, ainda que temporárias, para os problemas macroeconômicos e oportunidades de investimentos; nos locais as novas formas de 
uso e organização do território são quase sempre promotoras de conflitos e de maior segregação socioespacial.

\section{Bibliografia}

AB'SÁBER, A. (2003) Os domínios de natureza no Brasil. Potencialidades paisagísticas. São Paulo: Ateliê Editorial.

BANCO CENTRAL DO BRASIL. (2014) Anuário Estatístico do Crédito Rural. Série Histórica 2000/2012. Disponível em: http://www.bcb.gov.br/?RELRURAL. Acessado em: 24 mar. 2014.

BECKER, B. K.; EGLER, C. A. G. (1994) Brasil: uma nova potência regional na economia mundo. Rio de Janeiro: Editora Bertrand Brasil.

BERNARDES, J. A. (1996) As Estratégias do Capital No Complexo da Soja. In: CASTRO, I. E. de; GOMES, P. C. da C.; CORREAA, R. L. (orgs.) Brasil: questões atuais da reorganização do território. Rio de Janeiro: Ed. Bertrand Brasil. pp. 325366.

BERNARDES, J. A. (2006) Circuitos espaciais da produção na fronteira agrícola moderna: BR-163 mato-grossense. In: BERNARDES, J. A.; FREIRE FILHO, O. L. (orgs.) Geografias da soja: BR-163 fronteiras em mutação. Rio de Janeiro: Edições Arquimedes.

CASTELLS, M. (2003) A galáxia da internet: Reflexões sobre a Internet, os negócios e a sociedade. Rio de Janeiro: Jorge Zahar Editor.

CASTILlO, R. A. (2011) Agricultura globalizada e logística nos cerrados brasileiros. In: SILVEIRA, M. R. (org.). Circulação, transportes e território: diferentes perspectivas. São Paulo: Expressão Popular. pp. 331-354.

CENSO AGROPECUÁRIO IBGE. (1970) Disponível em: http://seriesestatisticas.ibge.gov.br. Acessado em: 10 nov. 2015.

. (1980) Disponível em: http://seriesestatisticas.ibge.gov.br. Acessado em: 10 nov. 2015.

. (1985) Disponível em: http://seriesestatisticas.ibge.gov.br. Acessado em: 10 nov. 2015.

(1995/96) Disponível em: http://seriesestatisticas.ibge.gov.br. Acessado em: 10 nov. 2015.

DAVIS, J. H.; GOLDBERG, R. A. (1957) A concept of agribusiness. Boston: Harvard University Press.

DELGADO, G. C. (1985) Capital financeiro e agricultura no Brasil, 1965-1985. São Paulo: Ícone/UNICAMP. 
DELGADO, G.C. (2012) Do capital financeiro na agricultura à economia do agronegócio: Mudanças cíclicas em meio século (1965-2012). Porto Alegre: UFRGS Editora.

DINIZ, B. P. C. (2006) O grande cerrado do Brasil central: geopolítica e economia. Tese (Doutorado em Geografia) - Programa de Pós-Graduação em Geografia Humana, Faculdade de Filosofia Letras e Ciências Humanas, Universidade de São Paulo. São Paulo.

ELIAS, D. (2011) Agronegócio e Novas Regionalizações no Brasil. Revista Brasileira de Estudos Urbanos e Regionais (ANPUR), v. 13. pp. 153-170.

ESALQ/CEPEA/USP (2013) Escola Superior de Agronomia "Luiz de Queiróz". Centro de Estudos de Economia Avançada. Indicadores de Preços (soja, trigo e milho), 2004 a 2013.

FREDERICO, S. (2010) O Novo Tempo do Cerrado: Expansão dos Fronts Agrícolas e Controle do Sistema de Armazenamento de Grãos. São Paulo: AnnaBlume.

GRAS, C.; HERNÁNDEZ, V. (2013) Los pilares del modelo agribusiness y sus estilos empresariales. In: (orgs.) El agro como negocio. Producón, sociedade y territórios em la globalización. Buenos Aires: Editorial Biblos.

HARVEY, D. (2004) O novo Imperialismo. São Paulo: Edições Loyola.

MACHADO, L. O. (1994) A Fronteira Agrícola na Amazônia Brasileira. Revista Brasileira de Geografia, Rio de Janeiro - RJ, v. 54, n 2. pp. 27-55.

MORAES, A. C. R. (2000) Bases da formação territorial do Brasil: o território colonial brasileiro no "longo" século XVI. São Paulo: Hucitec.

OLIVEIRA, A. U. (2010) A questão da aquisição de terras por estrangeiros no Brasil: um retorno aos dossiês. Revista Agrária, no 12. São Paulo. pp. 03-113.

PAM/IBGE. (2014) Instituto Brasileiro de Geografia e Estatística. Produção Agrícola Municipal. Série Histórica 1990-2012. Disponível em: http://www.sidra.ibge.gov.br/bda/pesquisas/pam/default.asp. Acessado em: 24 mar. 2014.

PECK, J.; TICKEL, A. (2002) Neoliberalizing Space. In: BRENNER, N.; THEODORE, N. Spaces of Neoliberalism: Urban Restructuring in North Americaan West Europe. Malden, USA: BlackwellPublishing.

REVISTA EXAME. (2011) As 50 maiores empresas do agronegócio. Exame negócios, 16 de novembro de 2011.

SANTOS, M. (1977) Sociedade e espaço: a formação social como teoria e como método. Boletim Paulista de Geografia. São Paulo: AGB. pp. 81- 99.

SANTOS, M. (1979) Economia espacial: críticas e alternativas. São Paulo: Hucitec. 
. (1994) Por uma economia política da cidade. São Paulo: Hucitec /Educ.

Paulo: Hucitec, 1996.

(1996) A natureza do espaço: Técnica e tempo. Razão e emoção. São . (1999) Guerra dos lugares. Folha de São Paulo. Caderno Mais! . (2000) Por uma outra globalização: do pensamento único à consciência universal. Rio de Janeiro: Record.

; SILVEIRA, M. L. (2001) O Brasil: Território e sociedade no início do século XXI. São Paulo: Record.

SAUER, S.; LEITE, S. P. (2011) Agrarian structure, foreign land ownership and land value in Brazil, In : International Conference on Global Land Grabbing, 6-8 avril, Sussex, 36 p.

SECEX/MDIC. (2014) Secretaria do Comércio Exterior. Ministério do Desenvolvimento, Indústria e Comércio Exterior. Estatísticas de Comércio Exterior. 2010. Disponível em: http://www.mdic.gov.br. Acessado em: 20 mar. 2014.

SILVA, A. B. (2001) São Paulo, produção de informações e reorganização do território brasileiro. Tese (Doutorado em Geografia Humana) - FFLCH, Universidade de São Paulo. São Paulo.

SILVEIRA, M. L. (2010) Região e globalização: pensando um esquema de análise. Revista Redes, Santa Cruz do Sul, v. 15, n 1 , jan./abr. pp. 74-88.

. (2011) Território usado: dinâmicas de especialização, dinâmicas de diversidade. Ciência Geográfica, XV, vol. XV (1), jan./dez. Bauru. pp. 04-12. 